\title{
ERS Clinical Research Collaborations: underpinning research excellence
}

\author{
Chris Brightling ${ }^{1}$, Celine Genton ${ }^{2}$, Werner Bill ${ }^{2}$, Tobias Welte ${ }^{3}$, Mina Gaga ${ }^{4}$, \\ Elise Heuvelin ${ }^{2}$ and Guy Brusselle 5,6
}

Affiliations: ${ }^{1}$ Leicester NIHR Biomedical Research Centre, University of Leicester, Leicester, UK. ${ }^{2}$ European Respiratory Society, Lausanne, Switzerland. ${ }^{3}$ Dept of Respiratory Medicine, Hannover Medical School, Hannover, Germany. "Respiratory Medicine Dept and Asthma Center, Athens Chest Hospital "Sotiria”, Athens, Greece. ${ }^{5}$ Dept of Respiratory Medicine, Ghent University Hospital, Ghent, Belgium. ${ }^{6}$ Depts of Epidemiology and Respiratory Medicine, Erasmus Medical Center Rotterdam, Rotterdam, The Netherlands.

Correspondence: Chris Brightling, University of Leicester, Glenfield General Hospital, Leicester, LE3 9QP, UK. E-mail: ceb17ale.ac.uk

@ERSpublications

The ERS Clinical Research Collaborations (CRCs) programme provides support to projects in different areas of respiratory medicine, to build and maintain pan-European and/or global collaborations. CRC applications can be submitted annually by October 15. http://ow.ly/34s730lxgnw

Cite this article as: Brightling C, Genton C, Bill W, et al. ERS Clinical Research Collaborations: underpinning research excellence. Eur Respir J 2018; 52: 1801534 [https://doi.org/10.1183/13993003.015342018].

The European Respiratory Society (ERS) mission is to promote respiratory health in order to alleviate and prevent suffering from respiratory disease. To achieve this mission there remains a number of challenges to be addressed. We need: 1) a better understanding of the burden of lung disease and its natural history, as well as of the fundamental mechanisms underpinning disease; 2) validation and application of accurate diagnostic tests, patient-centred outcomes and biomarkers; and 3) development and testing of new pharmacological and non-pharmacological interventions and their optimal implementation in clinical practice. To address these challenges adequately requires collaborative working between clinicians, allied health professionals, scientists, technology and pharmaceutical industries, regulators, healthcare providers and, most importantly, patients.

Respiratory research consortia and clinical networks are not a new concept but have typically worked in silos with variable links to the ERS [1]. In 2013, the ERS established the Clinical Research Collaborations with the aim of: promoting the exchange of research ideas among clinicians and affiliated scientists in Europe and/or globally; building an infrastructure for prospective clinical research; securing additional funding through national and EU funding streams; and facilitating the planning, conducting, evaluation and publishing of clinical and translational studies at pan-European level and beyond.

There are currently 17 ongoing ERS Clinical Research Collaborations, representing all eight major respiratory disease domains (airway diseases, interstitial lung diseases, pulmonary vascular diseases, sleep and breathing disorders, respiratory critical care, paediatric respiratory diseases, respiratory infections and thoracic oncology). These ERS Clinical Research Collaborations are linked to the respective ERS assemblies and summarised in table 1. Clinical Research Collaborations applications can be submitted annually by October 15. Each ERS Clinical Research Collaboration is funded for 3 years with the opportunity to apply for one funded renewal period. The ERS Clinical Research Collaborations encompass a vast spectrum of pan-European and/or global collaborations, including disease-specific paediatric and adult clinical registries for common and rare lung diseases (the latter in close collaboration and partnership with 
TABLE 1 The European Respiratory Society (ERS) Clinical Research Collaborations (CRCs)

\begin{tabular}{|c|c|c|}
\hline Start date & Project: acronym and title & CRC Chairs \\
\hline 2018 & CADSET: Chronic airway diseases early stratification & Alvar Agustí, Jadwiga Wedzicha \\
\hline 2018 & EARCO: European alpha-1 research collaboration & Marc Miravitlles, Timm Greulich \\
\hline 2018 & $\begin{array}{l}\text { WEAN SAFE: Worldwide assessment of separation of patients from } \\
\text { ventilator assistance }\end{array}$ & John Laffey, Leo Heunks \\
\hline 2017 & PEX-NET: Pulmonary haemodynamics during exercise - research network & Horst Olschewski, Philippe Herve \\
\hline 2017 & $\begin{array}{l}\text { SHARP: Severe Heterogeneous Asthma Research collaboration, } \\
\text { Patient-centered }\end{array}$ & $\begin{array}{l}\text { Ratko Djukanović, Elisabeth Bel, } \\
\text { Dominique Hamerlijnck, Toni Latimer-Gibson }\end{array}$ \\
\hline 2016 & ARIANE-IPF: ERS pan-European IPF registry and biobank & Bruno Crestani, Vincent Cottin \\
\hline 2016 & $\begin{array}{l}\text { ChILDEU: The European research collaboration for Children's Interstitial } \\
\text { Lung Disease }\end{array}$ & Steve Cunningham, Nico Schwerk \\
\hline 2015 & ENIRRIs: The European Network for ICU-Related Respiratory Infections & Antoni Torres, Ignacio Martin-Loeches \\
\hline $\begin{array}{l}\text { 2015, renewed } \\
\text { in } 2018\end{array}$ & ESADA: European Sleep Apnoea Database & Jan Hedner, Marisa Bonsignore \\
\hline $\begin{array}{l}\text { 2015, renewed } \\
\text { in } 2018\end{array}$ & TBNET: Tuberculosis Network European Trials group & Frank ven Leth, Graham Bothamley \\
\hline $\begin{array}{l}\text { 2014, renewed } \\
\text { in } 2017\end{array}$ & $\begin{array}{l}\text { EMBARC: European Multicentre Bronchiectasis Audit and Research } \\
\text { Collaboration }\end{array}$ & James Chalmers, Eva Polverino \\
\hline $\begin{array}{l}\text { 2014, renewed } \\
\text { in } 2017\end{array}$ & $\begin{array}{l}\text { INCIRCLE: INternational Collaboration to Improve Respiratory health in } \\
\text { Children }\end{array}$ & Peter Sly, Zoltan Hantos \\
\hline
\end{tabular}

ERN-LUNG) [2], bio-resource collections and trial platforms, as well as studies of early disease and standardisation of lung function and exercise testing. These ERS Clinical Research Collaborations map onto the eight major respiratory disease areas and the respective assemblies of the ERS as illustrated in figure 1. The inaugural ERS Clinical Research Collaborations were in bronchiectasis (EMBARC [3]) and paediatric lung disease (INCIRCLE). An ERS Clinical Research Collaborations working group led by the ERS Clinical Research Collaborations Director and reporting to the Science Council assesses new applications, and oversees and supports ongoing success. Potential gaps in the ERS Clinical Research Collaborations portfolio are met by the highlight notices to encourage applications from areas of research hitherto unrepresented. Connectivity between the ERS Clinical Research Collaborations is encouraged to disseminate best practice and to align government structures. Support for the ERS Clinical Research Collaborations is provided through the research agency of the ERS Science Council [4], which aims to contribute to the coordination of project conduct and the implementation of standards (data privacy and data models, etc.). Importantly, the ERS research agency in partnership with several ERS Clinical Research Collaborations has sought external grant funding through EU funding programmes such as Horizon 2020 and the Innovative Medicines Initiative and has established successful industry collaborations.

The ERS Clinical Research Collaborations also provide the opportunity to underpin the development and conduct of pragmatic trials. Pragmatic trials need to reflect real-life clinical practice in different healthcare settings; be generalisable and scalable to have sufficient impact on clinical practice. The ERS will endorse pragmatic trials in different respiratory disease domains that meet stringent criteria of quality and independence, and their success are likely to be predicated on either evolving from or working with the established ERS Clinical Research Collaborations [5].

The European Lung Foundation (ELF) plays a central role in the ERS Clinical Research Collaborations; ELF is integral in the working group and provides support to ensure patient involvement and engagement in the initiation, conduct and delivery of the research. Early career member involvement is strongly encouraged in the ERS Clinical Research Collaborations to support their career development as well as encourage sustainability and succession planning. 


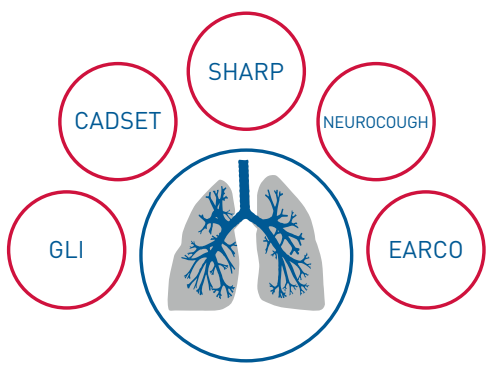

Airway

diseases

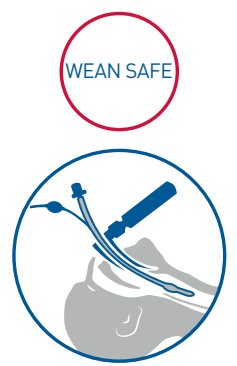

Respiratory critical care

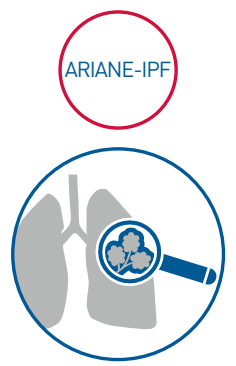

Interstitial lung diseases

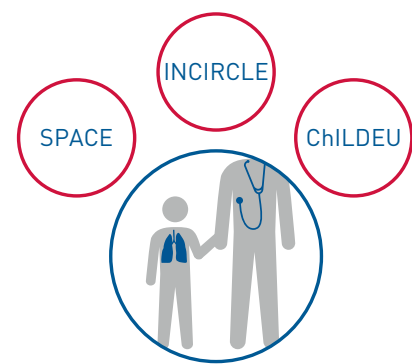

Paediatric respiratory diseases

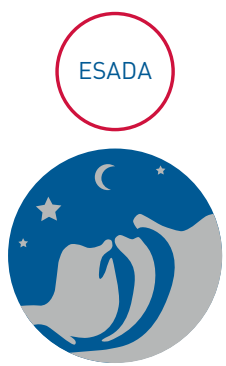

Sleep and breathing disorders

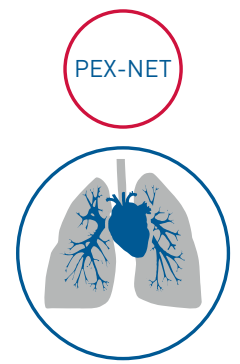

Pulmonary vascular diseases

FIGURE 1 Mapping of the European Respiratory Society Clinical Research Collaborations onto the eight main respiratory disease areas.

A successful ERS Clinical Research Collaboration is addressing an area of important clinical unmet need; has broad engagement to represent all stakeholders and has sufficient involvement of national respiratory societies, patients and early career members to ensure optimal implementation of the research findings into clinical practice and continuing success beyond the ERS funding period. The family of ERS Clinical Research Collaborations [6] will underpin the research excellence of our Society, and forthcoming editorials in the European Respiratory Journal will provide details of the aims and successes of the individual Clinical Research Collaborations.

Conflict of interest: C. Brightling reports grant and fees for consultancy (paid to institution) from GlaxoSmithKline, AstraZeneca/Medimmune, Novartis, Boehringer Ingelheim, Chiesi and Roche/Genentech, personal fees for consultancy (paid to institution) from Vectura, Theravance, PreP, Gilead, Sanofi/Regeneron, Teva, Gossamer and 4DPharma, and institutional grants from Pfizer and Mologic, outside the submitted work. C. Genton reports multi-sponsored study fees from Chiesi, Sanofi, Grifols, Novartis, Insmed, Zambon, TEVA and GlaxoSmithKline, outside the submitted work. C. Genton is an employee of the ERS. W. Bill is executive director of the ERS. T. Welte reports institutional grants from AstraZeneca, Bayer, Grifols, Insmed, Novartis, Pfizer and Boehringer, and personal fees for advisory board work and lectures from AstraZeneca, Bayer, Boehringer, GSK, Grifols, Insmed, Novartis, Sanofi and Pfizer, outside the submitted work. M. Gaga has nothing to disclose. E. Heuvelin reports multi-sponsored study fees from Chiesi, Sanofi, Grifols, Novartis, Insmed, Zambon, TEVA and GlaxoSmithKline, outside the submitted work. E. Heuvelin is an employee of the ERS. G. Brusselle reports personal fees for advisory board work and speaking from AstraZeneca, Boehringer-Ingelheim, Chiesi, Novartis, GlaxoSmithKline and Teva, and personal fees for advisory board work from Sanofi, outside the submitted work.

\section{References}

1 Djukanović R, Brusselle G, Walker S, et al. The era of research collaborations: new models for working together. Eur Respir J 2017; 49: 1601848.

2 Humbert M, Wagner TO. Rare respiratory diseases are ready for primetime: from Rare Disease Day to the European Reference Networks. Eur Respir J 2017; 49: 1700085.

3 Chalmers JD, Crichton M, Goeminne PC, et al. The European Multicentre Bronchiectasis Audit and Research Collaboration (EMBARC): experiences from a successful ERS Clinical Research Collaboration. Breathe 2017; 13: 180-192.

4 Soriano JB, Paton J, Burrieza FM, et al. The ERS Research Agency: the beginning. Eur Respir J 2016; 47: 1017-1023.

5 Pilette C, Brightling C, Lacombe D, et al. Urgent need for pragmatic trial platforms in severe asthma. Lancet Respir Med 2018; 6: 581-583.

6 European Respiratory Society. The ERS Clinical Research Collaborations. www.ersnet.org/research/clinical-researchcollaborations 